\title{
La antropología al servicio del Estado: El Instituto «Bernardino de Sahagún» del CSIC (1941-1970).
}

Está por hacer la historia de la investigación científica en España durante el franquismo, etapa en la que el Consejo Superior de Investigaciones Científicas (CSIC) aglutina y orienta una parte importante de esa labor investigadora '. El conocimiento de los distintos elementos e ideas que se articulan en torno a esta institución nos daría unas pautas interesantes para interpretar el papel jugado por la antropología y la etnología en el conjunto de las disciplinas científicas y humanísticas que se desarrollan en el CSIC. Al carecer de estas bases previas, debemos limitarnos, en este trabajo, a analizar el Instituto «Bernardino de Sahagún» de Antropología y Etnología (IBS) y su obra desde su propio entorno y en sus relaciones con las instituciones y organismos de temática afín del propio Consejo y la Universidad. Comenzaremos intentando delimitar el concepto de investigación científica que se postula para el CSIC en su ley fundacional y cómo aquél se proyecta hacia el IBS.

El preámbulo de la ley de creación del Consejo, de 24 de noviembre de 1939, manifiesta de forma palpable la indisoluble unión que se plantea entre la investigación científica y el nuevo estado. El deseo de «renovar la gloriosa tradición científica» de España se debe cimentar «en la restauración de la clásica y cristiana unidad de las ciencias, destruida desde el siglo XVIIII. Para ello hay que subsanar el divorcio y discordia [existente] entre las ciencias especulativas y ex-

* Abreviaturas empleadas:

- AGA, EC: Archivo General de la Administración, Sección de Educación y Ciencia (Alcalá de Henares); en dicha sección se guarda, en calidad de depósito, la mayor parte del archivo del CSIC.

- CSIC: Consejo Superior de Investigaciones Científicas.

- IBS: Instituto «Bernardino de Sahagún» de Antropología y Etnología.

Este artículo fue leído en el V Congreso de Antropología celebrado en Granada en diciembre de 1990 , cuyas actas aún no han sido publicadas.

1 Existe, no obstante, un estudio muy general sobre esta cuestión: P. GoNZÁleZ Blasco y J. Jiménez BlANCO, «La investigación en el Consejo Superior de Investigaciones Científicas. Estudio de un grupo significativo durante el período 1940-1955», en P. González Blasco, J. Jiménez Blanco y J. M. López Piñero, Historia y sociología de la ciencia en España (Madrid: Alianza Editorial, 1979), 126-162. 
perimentales» ${ }^{2}$. La «discordia» que se menciona tiene, obviamente, un sentido ideológico y es desde esta misma ideología del estado franquista desde la que se pretenden unificar las disciplinas científico-técnicas y las humanísticas. El mismo texto define con claridad en qué consiste esa «unidad de las ciencias»: «Hay que imponer, en suma, al órden (sic) de la cultura, las ideas esenciales que han inspirado nuestro Glorioso Movimiento, en las que se conjugan las lecciones más puras de la tradición universal y católica con las exigencias de la modernidad» 3 . Lo fundamental no es, de este modo, unir ciencias experimentales y humanidades (que también se pretende) sino fundir ciencia y religión, rechazando la autonomía e independencia que caracteriza al pensamiento libre desde el siglo XVIII y que había hecho suyas la II República.

Es evidente que, ante tales planteamientos, la antropología y la etnología habían de verse totalmente mediatizadas, si no hemos de decir, simplemente, manipuladas. Debía desaparecer de sus contenidos y principios esenciales toda referencia opuesta o no coincidente con los dogmas de la fe católica (sobre todo de carácter evolucionista o materialista) al tiempo que se integraban en ellos los postulados eugénicos de mejora de la raza, triunfantes entonces en buena parte de Europa, especialmente entre las potencias fascistas.

Todo esto queda plasmado en el decreto de 26 de septiembre de 1941 por el que se crea el IBS. Dicho decreto, como la ley fundadora del CSIC, lo firma el ministro de Educación José Ibáñez Martín, y su preámbulo (orientado sin duda por Pérez de Barradas y quizás también por el P. José María Albareda) es muy significativo. Se refiere, como era de esperar, al descubrimiento del Nuevo Mundo y afirma:

Pronto, a la sorpresa admirativa del orbe cristiano, ante los descubrimientos y las hazañas de nuestros navegantes, soldados y misioneros, siguió, en pleno Imperio hispánico, la observación desapasionada, la reflexión y, con ello, la creación de una ciencia núclea que es obra hispánica: la Etnología, fundacionalmente española y exclusivamente católica durante dos siglos ${ }^{4}$.

El tan traído y llevado «nacionalismo en la historia de las ciencias» tiene aquí un magnífico ejemplo sobre cuyo contenido, sin embargo, no se va a insistir apenas en años posteriores. Sí se reiterarán afirmaciones y planteamientos, durante el franquismo, acerca de la segunda gran idea expresada en el párrafo citado: el carácter católico de la et-

\footnotetext{
2 Memoria de la Secretaria General. 1940-41 (Madrid: CSIC, 1942), 383.

idem.

+ Ibid.. 431 .
} 
nología española que, además, va a quedar indisolublemente unida a la idea de Imperio:

Proyectada por una curva la línea de la Etnología en España, coincide su plenitud con la de nuestra grandeza e Imperio, hasta que su florecimiento y equilibrio se rompe en el siglo Xvili al acabar la 'clásica y cristiana unidad de las ciencias'

De esta visión sobre la historia de la etnología española se desprenden tres conclusiones evidentes: $1 .^{2}$ España es la nación fundadora de los estudios etnológicos; $2{ }^{2}$ La etnología ha sido una disciplina esencialmente española hasta el siglo XVIII; y 3. ${ }^{\star}$ La etnología no hubiera surgido como ciencia de no haber sido por la «feliz» conjunción histórica de un imperio, el español, y una religión, la católica.

La nueva etapa que se abre con el estado franquista reunifica los dos fundamentos que posibilitaron esa pretendida hegemonía española en las ciencias etnológicas: Imperio y Catolicismo. A partir de aquí, no deberían existir obstáculos teóricos para el desarrollo de los estudios etnológicos y antropológicos en España; y es para fomentarlos por lo que se crea el IBS. El decreto de fundación ya citado señala de manera concisa las funciones de dicho instituto:

a) El estudio antropológico del pueblo español, tanto en el pasado como en el presente, y tanto sobre el individuo vivo como sobre su esqueleto, creándose, cuando sea oportuno, las Secciones de crecimiento infantil, tipología constitucional y endocrina, hematoantropología y herencia.

b) El estudio de las costumbres, artes y creencias populares de España, Marruecos y Colonias ${ }^{6}$.

Esta doble funcionalidad (antropología - física - y etnología) asume la reiterada idea de la «unidad de las ciencias». Al mismo tiempo, dicha orientación se convertirá en uno de los factores clave que impidan el desarrollo autónomo de la etnología o la antropología cultural.

El nuevo centro quedaba integrado por «el Museo Etnológico, con sus colecciones, biblioteca y toda clase de material»-que se constituía, asimismo, como sede- y «las colecciones etnográficas del Museo Arqueológico Nacional, salvo las que se refieren a América y Filipinas» ?

5 Ídem.

6 Ibid., 432.

7 Ídem. Puede parecer extraño que las colecciones etnográficas de Filipinas pertenecientes al Museo Arqueológico no fueran incorporadas al Museo Etnológico - y en definitiva al IBS-, teniendo en cuenta que este museo disponía de la mejor colección española sobre ese ámbito geográfico. Esto se explica por el hecho de que oficialmente el Museo de América lo era también de Filipinas y a él se pretendian agregar las colecciones citadas. En cualquier caso, solo recientemente el Museo Arqueológico ha entregado sus colecciones etnográficas al Etnológico. 
A esta estructura museística se añadía la labor propia de un centro de investigación.

El edificio del citado Museo Etnológico Nacional - hoy Museo Nacional de Etnología - va a albergar al IBS (la dirección y la sección de Madrid) hasta 1962, a pesar de que en 1952 el museo se independiza, contando desde entonces con director propio. Hasta esta última fecha, la conjunción de intereses y actuaciones entre museo e instituto no se puede entender sólo por el hecho de que ambos centros formen una única institución. El factor fundamental que lo explica lo encontramos en la circunstancia de que es una misma persona quien ocupa la dirección del museo (hasta su fusión con el IBS) y la del nuevo instituto; se trata de José Pérez de Barradas. Éste había sido nombrado secretario del museo nada más concluir la guerra, en mayo de 1939, y un año después accedía a la dirección, que había ocupado interinamente tras la jubilación de Francisco de las Barras el 28 de octubre de 1939.

En el mismo año de 1939, Pérez de Barradas era nombrado director del Museo del Pueblo Español, cargo del que dimitiría en 1944 para dedicarse plenamente al IBS. En resumen, durante los primeros años de la postguerra -en el período de despegue del nuevo estado franquista- Barradas va a tener bajo su dirección todos los centros e instituciones estatales existentes en Madrid que se dedican a la investigación etnológica y antropológica: Museo del Pueblo Español, Museo Etnológico Nacional, Instituto Bernardino de Sahagún y Cátedra de Antropología de la Facultad de Ciencias, que obtiene en 1941. No es necesario destacar lo que esto supone en cuanto a la consideración científico-política de la personalidad de P. de Barradas por parte del régimen, como tampoco hace falta llamar la atención sobre el papel que jugó en la orientación de los estudios antropológicos oficiales durante estos años.

Pero volvamos al IBS. Como ya hemos indicado, el decreto fundacional es de septiembre de 1941, por lo que hasta bien entrado 1942 el Instituto no tendrá posibilidades de entrar en funcionamiento como tal. No obstante, Barradas comienza a trabajar inmediatamente para su puesta en marcha, proponiendo colaboradores honorarios y presentando a la aprobación de la presidencia del CSIC el reglamento del nuevo Instituto, escrito sobre el que más adelante volveremos. El personal que aparece trabajando en 1940-41 en el museo, y que pasa automáticamente a formar parte del IBS, es el siguiente: José Pérez de Barradas, director; M." de las Mercedes González Jimeno, secretaria; Caridad Robles Mendo, 
becaria de la sección de bioantropología; Julio Caro Baroja y Julio Cola Alberich, becarios de la sección de etnología ${ }^{8}$.

Nos centraremos ahora en los primeros proyectos de investigación diseñados por P. de Barradas para dar inicio a las actividades del Instituto. En marzo de 1942 remite a la presidencia del CSIC un reglamento para el funcionamiento del IBS acerca del cual parece que no obtuvo respuesta alguna (AGA, EC, 8537, oficio de 10-III-42). Vuelve a repetir el envío en el mes de octubre; se trata del mismo escrito anterior que, sin embargo, incluye algunas adiciones muy significativas (AGA, EC, 8540, oficio 30-X-42). Vamos a examinarlo brevemente. En dicho reglamento se indica que el IBS tendrá dos funciones principales: la de museo y la de centro de investigación. Como tal centro, el objetivo fundamental a cumplir será:

(...) el estudio del hombre español sano y normal, sus variaciones regionales y sus relaciones con paises (sic) vecinos, para poder establecer los límites con lo patológico y para cometer (sic) empresas de tan alto valor nacional como la del mejoramiento de la raza.

A continuación, se detallan las funciones del director (que detenta un control absoluto sobre el centro) y del vicedirector. Entre estas últimas, la segunda versión del reglamento incluye dos que no aparecían en la primera:

3. Representar al Instituto ante la Dirección General de Sanidad y ante todos aquellos organismos a quienes interesen los resultados prácticos de las secciones de Antropobiología en lo que se refiere a la degeneración racial y a las medidas profilácticas y sociales para el mejoramiento de la raza.

4. Organizar el curso del Grupo de Damas, de cursillos y conferencias para preparar médicos para la campaña del mejoramientos de [la] raza (...)

El artículo $6 .^{\circ}$ enumera las secciones en que se pretende organizar el área de antropología: raciología, osteología («que lleva aneja la ordenación y conservación de la parte correspondiente del Museo»), herencia humana, tipología constitucional, alimentación, psicotipología, ti-

8 En 1940 trabajan también en el museo Julio Martínez Santa-Olalla (como jefe de la sección de paletnología) y los becarios M.a Luisa Montalvo, Guillermo Alonso del Real y Modesto Gómez. El CSIC había aceptado estas propuestas de personal pero parece que no llegaron a efectuarse los nombramientos oficiales. Cuando comienza a funcionar el IBS no hay referencia alguna a que continúen en el centro. Ver oficio de P. de Barradas a la Secretaría del CSIC de 31 de octubre de 1940 y otros escritos anteriores conservados en AGA EC, leg. 8531, s/n. 
pología endocrina, crecimiento infantil, hematoantropología, degeneración racial, mesología, demografía y antropología femenina. De éstas, las de degeneración racial, mesología y demografía no se incluían en la primera versión del reglamento, en el cual se indicaba, además, que ya estaban en funcionamiento la última y las cuatro primeras secciones que acabamos de enumerar.

El texto reglamentario concluye señalando que «cuando estén próximas a terminarse las obras de las salas del Museo y del resto del edificio, se dictarán las normas para el funcionamiento del Museo Etnológico, colecciones osteológicas y se organizará el grupo de secciones de Etnología». Como podremos comprobar a lo largo de este trabajo, el área de investigación etnológica estará siempre en clara desventaja en el IBS frente a la de antropología física.

Volviendo a los proyectos iniciales de estudio que se plantean en el reglamento del IBS, vemos que es la parcela relativa a la «mejora de la raza» la que más parece interesar a su director. Precisamente P. de Barradas utiliza este planteamiento como reclamo de su labor ante las autoridades científico-políticas. Para éstas, los planes de regeneración moral y la idea de conseguir un «nuevo hombre español» y una «nueva España» estaban íntimamente conectados con la depuración y mejora de la «estirpe racial», tratando de seguir, aunque sólo en parte, el camino trazado por la todavía triunfante Alemania nazi y la Italia fascista. Es bastante ilustrativo al respecto el oficio que dirige Barradas a la presidencia del Consejo el 23 de julio de 1942, solicitando un crédito extraordinario de 50.000 pesetas (que parece no consiguió). En dicho escrito, que reproducimos por extenso debido a su representatividad, se indica lo siguiente:

Es necesario, mejor una necesidad urgente, el que en nuestra patria se emprenda el estudio del hombre español desde el punto de vista de las nuevas orientaciones antropobiológicas en el cual se ha de obtener grandes resultados prácticos, que afectan, no sólo a la Medicina en general, sino a problema de trascendencia tan capital como el mejoramiento del futuro biológico de nuestro pueblo.

Precisa el que nos conozcamos los españoles a nosotros mismos, en lo que se refiere al hombre sano y normal, el investigar sus leyes de crecimiento, sus variaciones tipológicas, constitucionales y endocrinas y los problemas de herencia, como labor previa para emprender la gran tarea, de indiscutible urgencia, de mejorar nuestra estirpe racial. Esta preocupación debe ser tanto mayor cuanto que la raza mediterránea a que pertenecemos, que es una de las mejor dotadas biológicamente y que tiene una gran facilidad de adaptación, muestra tendencias a un empobrecimiento vital, las cuales han sido señaladas hace años en Portugal y en Italia, en donde la campaña iniciada hace dos años por el doctor Nicolás Pende ha culminado en la creación del Instituto Nacional Biotipológico Ortogénico, con 
un presupuesto de más de diez millones de liras y la creación de la cátedra de Biotipología humana, en la Universidad de Roma, donde se preparan los médicos para la lucha por la mejora biológica del hombre italiano.

A estos fines ha obedecido la creación del Kaiser Wilhem Instituto de Antropología, que funciona en Darhein, cerca de Berlín desde 1928 y el últimamente creado en Francia bajo la dirección del doctor Alexis Carrel. Trátase, en suma, de una preocupación mundial agravada por los momentos actuales en que atraviesa el Mundo, a la cual no podemos permanecer aparte (AGA, EC, 8537).

En la memoria de actividades correspondiente a ese mismo año de 1942, se puede leer también:

El Dr. Pérez de Barradas ha dedicado su atención preferentemente, en Antropobiología, al estudio de los métodos para un estudio (sic) completo del poder vital del pueblo español, que sirva para promover la regeneración de nuestra raza y evitar los factores degenerativos de la misma, con lo cual se sale de la Antropología estática para seguir las nuevas orientaciones de la Antropología dinámica".

Entre esos métodos de trabajo que estudia Barradas, se encuentra el organizar un «curso para la formación de un Grupo honorario de Damas», con el fin de que «colaboren a la labor de reconocimiento de casos femeninos y de niños, que investiguen las condiciones ambientales de cada caso, así como las posibles alteraciones endocrinopáticas y constitucionales en general, los antecedentes hereditarios, etc.». Todo ello para alcanzar «los fines perseguidos por la sección de Antropobiología en la lucha por el mejoramiento de la raza» (AGA, EC, 8537, oficio de $30-X-42$ ).

Continuando con el desarrollo institucional del IBS, podemos señalar que en la Memoria del CSIC correspondiente a 1944 aparecen citados dos nuevos miembros: Santiago Alcobé, como vicedirector y Jesús Fernández Cabeza, como secretario. El primero va a ser además jefe de la sección de antropobiología que se instala ese mismo año en Barcelona. Las tareas desarrolladas en esta sección durante 1945 se estructuran en cinco apartados: 1. «Estudios del crecimiento en escolares barceloneses», por Antonio Prevosti; 2. "Antropología Histórica de España», con trabajos de Prevosti, Miguel Fusté y José Pons sobre cráneos y esqueletos neolíticos y de época romana; 3. "Antropología de poblaciones actuales», con estudios de antropología física de Alcobé sobre nómadas del Sáhara y pobladores del Pirineo, estos últimos en colaboración con Prevosti; 4. «Estudio tipológico de la mano humana», por Fusté; y 5. «Organización de un archivo antropológico».

9 Memoria de la Secretaría General. 1942 (Madrid: CSIC, 1943), 163. 
También en Barcelona, en 1945, se crea una sección de etnografía del IBS, que tiene como base el Arxiu d'Etnografia i Folklore de Catalunya organizado por Tomás Carreras i Artau. En él trabajan, sobre etnografía catalana y pirenaica, Ramon Violant, Joan Amades y Aureli Capmany (como becario), incorporándose más adelante Augusto Panyella. Este mismo año de 1945 se creaba una nueva sección, de antropología médica, en Valladolid, dirigida por Misael Bañuelos. Su labor será mínima, desapareciendo a la muerte de Bañuelos, en 1956.

En 1946 el IBS deja de pertenecer al patronato «Menéndez Pelayo», de Historia y Filosofía, y pasa al «Ramón y Cajal», de Ciencias Médicas y Biología animal. La decantación hacia la antropología física es casi absoluta.

Como consecuencia de la realización de un viaje de estudios por Colombia entre julio y noviembre de 1946, Pérez de Barradas decidió otorgar la categoría de sección americana del IBS al «Centro de Investigaciones Lingüísticas y Etnológicas de la Amazonia Colombiana», dirigido por el capuchino Fr. Marcelino de Castellví, en Sibundoy. Precisamente éste, en 1949, propuso al secretario general del CSIC (J. M. ${ }^{a}$ Albareda) la creación de un Centro de Etnología Americana en Barcelona, bajo su dirección. Albareda solicitó parecer a Luis Pericot y Santiago Alcobé, quienes informaron negativamente, y con razón, el proyecto "panantropológico» de Castellví (AGA, EC, 8602). Barradas, sin embargo, tendrá siempre en gran consideración la obra científica del misionero capuchino.

El período comprendido entre 1945 y 1952 representa el momento álgido de desarrollo del IBS en su núcleo central de Madrid. Su estructura interna está ya consolidada y se organiza en secciones de osteología, morfología, fisiología antropológica y grupos sanguíneos, crecimiento infantil y etnología. No obstante, no podemos dejar de insistir en el hecho de que la etnología acaba ocupando una única sección, en clara desventaja respecto a la antropología física. En 1945 consiguen editar el primer número de la revista Trabajos del Instituto Bernardino de Sabagún de Antropologia y Etnología. En 1949 esta publicación pasa a ser editada por la sección de antropobiología de Barcelona, mientras que en Madrid se crea una nueva: Antropología y Etnologia, de la que aparecen catorce números hasta 1961. La actividad investigadora del IBS tiene en 1948 un hito importante. En el verano de ese año Santiago Alcobé dirige la «Expedición a los territorios españoles del Golfo de Guinea», organizada por la Dirección General de Marruecos y Colonias y el Instituto de Estudios Africanos. El equipo de trabajo era interdisciplinar, siendo responsables de las investigaciones en antropología física 
Santiago Alcobé y Jesús Fernández Cabeza y de las etnológicas Augusto Panyella. No deja de llamar la atención que no participara en el proyecto Pérez de Barradas, aunque no podemos explicar las razones para que esto fuera así.

Hemos marcado el punto de inflexión, para el centro de Madrid, en 1952. En este hecho influye decisivamente la separación del Museo Etnológico respecto del IBS. La ruptura será bastante traumática para Pérez de Barradas, quien parece ser que durante algún tiempo siguió considerando al museo como centro dependiente del IBS, aunque aquél disponía ya de director propio en la persona de José Tudela de la Orden ${ }^{10}$. Por otra parte, pasan a ser colaboradoras del museo, abandonando el IBS, M. de las Mercedes González y Caridad Robles. Estas seguirán dedicándose fundamentalmente a la antropología física, lo que no beneficiará en nada el desarrollo de la investigación etnológica del centro. La obligada e incómoda convivencia de ambos centros en el mismo edificio hasta 1962, unida a la necesidad de compartir presupuesto, hace inevitables los roces. Un ejemplo de la tensa situación que se vive puede ser el siguiente oficio enviado por $\mathrm{P}$. de Barradas al vicesecretario primero del CSIC el 10 de junio de 1958 :

El Alto Estado Mayor Central ha encomendado a este Instituto el estudio estadístico antropológico del soldado español, cuya documentación tiene el carácter de reservado, así como la elaboración del trabajo a realizar. Con esta fecha comunico lo anterior al Sr. Director del Museo Etnológico y que con el fin de evitar posibles indiscreciones e incidentes desagradables del personal que tiene a sus órdenes, y poder asumir por mi parte la responsabilidad plena de la reserva que se me ha encomendado, he resuelto dar las órdenes de cerrar los locales de este Instituto excepto las horas reglamentarias de 4 a 8 de la tarde, haciéndose la limpieza por cuenta del mismo (AGA, EC, 8921).

La progresiva disolución del IBS en Madrid es irreversible, lo que no impide que trabajen en él (en el ámbito de la antropología física) investigadores de relieve, como Arturo Valls. En 1960 se decidía en el Consejo que el IBS abandonara sus dependencias en el museo y pasara a ocupar unos locales de la Cátedra de Antropología en la Facultad de Ciencias. El traslado no parece que se hiciera, sin embargo, hasta 1962. El último escrito firmado por Pérez de Barradas que hemos localizado en el AGA es de octubre de 1967 y entonces la sección de Madrid del

10 Algunos años antes ya se habían originado serios problemas entre Barradas y la Sociedad de Antropología, que había tenido su sede en el museo. Cf. L. A. Sánchez GOMEZ, «La Sociedad Española de Antropología, Etnografía y Prehistoria (1921-1951)», Revista de Dialectologia y Tradiciones Populares, XLV (1990), 61-87. 
IBS se encuentra ya en los locales de la citada cátedra, en el pabellón quinto de la Facultad de Medicina, en la Ciudad Universitaria.

En Barcelona, Santiago Alcobé continúa presentando memorias de actividades hasta, al menos, 1970. El centro que dirige sigue apareciendo como sección de antropobiología del IBS, pero ya integrado plenamente en la Universidad de Barcelona.

¿Cómo valorar los resultados científicos del IBS? Por lo que se refiere al centro barcelonés, parece evidente que puede y debe deslindarse su labor con respecto al de Madrid. En aquél se producirá una progresiva especialización en la que era su área de investigación (la antropobiología) que le conduce al logro de un status científico muy notable, en el que, sin embargo, las relaciones con la etnología o la antropología cultural serán nulas. En cuanto a la sección de etnografía, también de Barcelona, constituida por el Arxiu, no corresponde a este trabajo su valoración ya que se enmarca en una tradición rica y compleja que, pese a vincularse al CSIC en estos años, debe analizarse desde otra perspectiva ".

Veamos lo que ocurre en Madrid. No creemos equivocarnos si señalamos que el IBS es el primer centro oficial de carácter estatal (no exlusivamente museístico) creado en España para la investigación etnológica y antropológica. Desde una perspectiva puramente teórica, el IBS pudo haberse convertido en el eje coordinador de las investigaciones sobre antropología física y cultural en España durante la etapa franquista, ya que disponía de la base legal e institucional suficiente para ello. Sin embargo, esto no ocurrió. Las circunstancias que impidieron este desarrollo óptimo fueron tanto de carácter coyuntural como estructural. Entre estas últimas, la fundamental hace referencia al atraso científico de nuestro país y que afecta al desarrollo de la antropología física y la cultural hasta casi hoy mismo, hecho que parece olvidarse en muchos estudios sobre historia de la antropología española. Por otra parte, y en relación con lo que acabamos de indicar, habría que hacer un detallado seguimiento de la actividad científica, institucional y profesional desarrollada en España en el ámbito de la antropología, comparándola con lo que ocurre fuera de nuestras fronteras.

Por lo que se refiere a los problemas coyunturales, creemos que pueden agruparse en cuatro grandes apartados: políticos, institucionales, académicos y personales. Veamos cada uno de ellos.

$"$ Puede consultarse al respecto la obra de L. Calvo Calvo, El "Arxiu d'Etnografía i Folklore de Catalunya" y la Antropologia Catalana (Barcelona: CSIC, 1991). 
El interés del estado franquista por crear un «nuevo hombre español» y «mejorar la raza» había favorecido la propia creación del IBS pero, con el transcurso del tiempo, esta interpretación práctica de la antropología se convertiría en un auténtico lastre para su desarrollo. La derrota de las potencias fascistas y el descrédito y ataque frontal del mundo científico al racismo antropológico y los postulados eugénicos, supusieron un duro golpe para la orientación antropológica defendida por Barradas. Éste, en sus obras posteriores a 1945, insistirá en su posición contraria al racismo, pero en las anteriores, aunque no defiende la discriminación racial tampoco critica las investigaciones y la práctica política racista de Alemania o Italia, más bien todo lo contrario ${ }^{12}$. Si a todo esto añadimos el aislamiento político y científico del país y el exilio de buena parte de la intelectualidad española, es evidente que el momento histórico-político vivido durante los primeros veinticinco años del franquismo era escasamente propicio para cualquier tipo de desarrollo científico que tuviera que conectar con corrientes o teorías originadas fuera de nuestras fronteras.

Pasemos ahora a las causas de carácter institucional. El IBS se había organizado tomando como base el Museo Etnológico. Aunque es precisamente en 1940 cuando se cambia su denominación, sustituyendo la anterior de Museo Antropológico, su orientación investigadora etnológica será mínima y ello pese a disponer de buenas colecciones museísticas sobre áreas culturales concretas. El lastre antropológico-físico del museo

1: Para valorar la actitud de Barradas ante el racismo es interesante conocer la agria polémica que mantuvo con Juan Comas. Se inicia con sendas reseñas de Comas sobre dos libros de Pérez de Barradas: el Manual de Antropología (1946) y Los Mestizos de América (1948). A estos comentarios siguen la réplica y contrarréplica de uno y otro autor. Los escritos que conforman dicha polémica son, en orden cronológico, los siguientes: J. Comas, [reseña de] «Pérez de Barradas, J., Manual de Antropologia», Actas y Memorias de la Sociedad Española de Antropologia, Etnografía y Prebistoria, XXIV (1949), 104-109; ÍD., "Reivindicación del Indio y lo indio», América Indígena, XI (1951), 129-146; íD., "La cristianización y educación del indio desde 1492 a nuestros días», ibid., 219-234; fD., «La realidad del trato dado a los Indígenas de América entre los siglos XV y XX», ibid., 323-370 [estos tres artículos de Comas reseñan las obras El protector de Indios, de C. Bayle (1945) y Los Mestizos de América, de Barradas (1948)]; M. Ballesteros GaibroIs, «Sección bibliográfica. Indigenismo», Revista de Indias, 45 (1951), 607-611 [son unos comentarios críticos sobre los tres artículos de Comas citados]; J. PÉREZ DE BARRADAS, «El indigenismo político y la actuación de España en América», Antropología y Etnologia, 4 (1951), 115-133; fD., «El indio y lo indio (a propósito de un artículo de Juan Comas)», Revista de Indias, 46 (1951), 751-760 |versión reducida del artículo citado anteriormente]; J. COMAS, «El indigenismo de J. Pérez de Barradas», Revista de Indias, 49 (1952), 547-562; 10., «Razón de ser del movimiento indigenista», América Indígena, XI (1953), 133-144. 
- herencia de setenta y cinco años de historia- es difícil de eliminar. Además, el propio $\mathrm{P}$. de Barradas asegura ser continuador de la tradición investigadora desarrollada por sus antecesores en el museo y la Cátedra de Antropología de la Facultad de Ciencias ${ }^{13}$. Exceptuando a Julio Caro Baroja, que trabajó unos años como becario en el museo, el resto del personal se dedica a la antropología física o la prehistoria de forma mayoritaria. Podríamos aventurar algunas conjeturas - totalmente inútiles por otra parte- y señalar que el desarrollo del IBS quizás hubiera sido distinto de haberse creado alrededor del Museo del Pueblo Español (por no salir de Madrid), por supuesto si su director hubiera sido otro, y no el mismo P. de Barradas como lo fue hasta 1944. Es cierto que el MPE tenía un marcado carácter «etnografista» y quizás «folklorista», pero con Luis de Hoyos al frente (y sin la guerra, claro) su separación -o relación más acertada- con respecto a la antropología física y la prehistoria podría haber quedado asegurada.

Por lo que se refiere a la cuestión académica, no podemos olvidar que el tardío desarrollo de la etnología en la Universidad tiene mucho que ver con la total dependencia e incluso subordinación de esta disciplina respecto de la prehistoria. Claudio Esteva expuso con detalle esta problemática en un escrito, ya clásico, en el que analizaba la situación de la etnología en el contexto universitario e institucional español 14; por ello, no vamos a insistir en el tema.

Vamos a detenernos, finalmente, en los condicionamientos personales que rodearon la labor del IBS. Ya hemos indicado que en el nuevo panorama científico que encontramos en España una vez concluida la guerra civil, los estudios antropológicos van a estar orientados (en el ámbito oficial estatal) por la figura de Pérez de Barradas. Sus influencias y contactos en estos primeros años de la postguerra debieron moverse a un alto nivel. Recordemos que pasó los años de la guerra en Colombia, donde había acudido en 1936 en viaje de estudios. Entonces ya era doctor en Ciencias Naturales, había sido vicepresidente de la Sociedad Española de Antropología, Etnografía y Prehistoria y director interino (luego investigador por oposición) del Servicio de Investigaciones Prehistóricas del Ayuntamiento de Madrid. En 1939 aparece como profesor encargado de la Cátedra de Antropología de la Facultad de

1; J. Pérez de Barradas, Manual de Antropología (Madrid: Cultura Clásica y Moderna, 1946), 2-3.

1 C. Esteva, «La Etnología española y sus problemas», Etnología y Tradiciones Populares (I Congreso Nacional de Artes y Costumbres Populares) (Zaragoza: Institución Fernando el Católico, 1969), 1-40. 
Ciencias, cátedra que obtendrá en propiedad en $1941^{15}$. Como ya hemos señalado, es también en 1939 (en mayo) cuando es nombrado secretario del todavía Museo Antropológico, luego director interino y poco después director titular. Estos nombramientos, y los que les siguen, son buena prueba de la confianza política y científica depositada en él por los altos cargos del Ministerio de Educación y el CSIC durante estos primeros años.

Pasando a la obra científica de Barradas, podemos señalar que es escasamente antropológica y etnológica, aunque entronca con la primera (en su orientación física) a través de la prehistoria y con la segunda mediante sus estudios etnohistóricos sobre Colombia. Pero ahora, más que valorar su trabajo, nos interesa adentrarnos en los conceptos de antropología y etnología que utiliza y que aplica, por tanto, a la labor de investigación del IBS. Ya hemos visto que la puesta en marcha del centro se realiza a partir de la antropología física, dejando la etnología en un segundo plano. Barradas desea impulsar la labor del Instituto incitando el interés de las autoridades con el recurso de ofrecer pautas y actividades concretas para la reiterada idea de «mejora de la raza». Hasta 1945 el lenguaje empleado en sus escritos aparece totalmente mediatizado por el discurso eugénico nazi-fascista, aunque amoldado al caso español y sin incluir factores de violencia o persecución racial. Durante estos primeros años, el arrinconamiento de la etnología no es sólo fruto de una dedicación minoritaria, lo que ocurre es que, como disciplina, tiene poco que aportar (aparentemente) a la citada empresa de la mejora racial.

Terminada la II Guerfa Mundial, y derrotadas las potencias fascistas, el discurso antropológico de Barradas se transforma, aunque continúa bebiendo de las mismas fuentes. Son dos los nuevos elementos que entran en juego: el descrédito y hasta rechazo de las teorías raciales en Europa y la constatación del terrible poder destructivo del hombre. La angustiosa situación que ha vivido y vive todavía el mundo incide de lleno en las formas de pensamiento filosófico. Barradas toma elementos aislados de algunas de estas nuevas (o renovadas) corrientes filosóficas (como el existencialismo) y los une a otros que había manejado ya con anterioridad (de Alexis Carrel, sobre todo) reconduciendo así su idea

15 P. Romero de TejadA, «La antropología española y el Museo Nacional de Etnología (1875-1974)", en M. Rivera Dorado (ed.), Antropología de España y América (Madrid: Dosbe, 1977), 295-322. 
acerca de la antropología y la etnología ${ }^{16}$. Va a sustituir en su discurso la idea de «mejorar la raza española» por la de profundizar en el conocimiento íntegro del Hombre, para comprenderle en toda su complejidad y poder evitar así tanto su progresivo deterioro vital y emocional como el que pueda provocar una nueva hecatombe mundial. $\mathrm{Su}$ argumento es que "pese a todos los fantásticos adelantos de nuestra época el Hombre no sólo no ha mejorado biológica y espiritualmente, sino que cuando ha tenido posibilidad ha mostrado una maldad inaudita e inconcebible» ${ }^{17}$. Y sigue:

La preocupación actual respecto al Hombre es, por una parte, pesimista y atea, es la desesperación de la bestia herida y el reconocimiento de la impotencia y de la nada (...). El primer paso para su rehabilitación es el reconocimiento humilde de no ser ni dueño del mundo ni de su destino, puesto que la transgresión de las leyes biológicas y morales tienen (sic) su castigo en la degeneración de los individuos y de los pueblos. Es saludable el que el Hombre se preocupe de que, pese a sus progresos técnicos, se automatiza y se embrutece, y más saludable aún el reconocimiento de que su salvación son los valores eternos. La Antropología filosófica nos lleva al fracaso cuando se aleja de la Antropología teológica ${ }^{18}$.

Existe un buen número de ciencias que estudian al Hombre, pero falta un conocimiento unitario. Según $P$. de Barradas ésta es la tarea que debe realizar la antropología, pero hasta ahora no se ha podido alcanzar dicho conocimiento por la desconexión existente entre las tres orientaciones básicas de esa antropología: científica, filosófica y teológica. Antes de ver cuáles son los conceptos que maneja sobre las «auténticas» antropología y etnología «científicas», vamos a resumir su opinión acerca del desarrollo histórico inmediato de ambas disciplinas. Considera errónea la orientación de la que denomina «antropología clásica», evolucionista, por considerar que el hombre debe ser estudiado «como una especie animal cualquiera» y por defender su evolución desde formas no humanas. Por lo que se refiere a la etnología, asegura que ha tenido dos inclinaciones. Una hacia las ciencias naturales, que fracasó debido a que "pretendía demostrar que entre las creaciones naturales y las culturales humanas no había diferencias fundamentales, sino de grado» ${ }^{19}$. Pero incluso la corriente etnológica que siguió dentro de las «ciencias cultu-

"J. PÉrez de Barradas, "Antropología y Etnología», Antropología y Etnología, 1 (1949), 9-19.

is Ibid., 9.
Ibid., 12.
Ibid., 15.


rales» «ha tardado en encontrar sus propias orientaciones, puesto que ha sufrido la influencia de las ideas filosóficas más dispares». Hace un rápido repaso de las mismas y concluye que la única fecunda ha sido la proveniente de la corriente histórico-cultural, con Frobenius, Graebner y el P. Schmidt al frente.

Veamos ahora cuáles son las conclusiones de Barradas acerca de lo que deben ser los objetivos que deben alcanzar la antropología y la etnología «científicas»:

La misión de la Antropología actual es echar los cimientos de un nuevo 'Humanismo', basado no en el estudio del Hombre contemporáneo, ni el que podemos conocer por los clásicos griegos y romanos, sino por todo el conjunto de la Humanidad. En cuanto al problema biológico, la Antropología aspira a conseguir un conocimiento exacto del Hombre, tanto más urgente cuanto que desaparecen las razas primitivas ante nosotros por las colonizaciones, las guerras, las enfermedades y el mestizaje ${ }^{20}$.

Por lo que se refiere a la etnología (y citando al antropólogo italoargentino José Imbelloni) asegura que:

(...) es la ciencia de nuestro tiempo, puesto que su fin es comprender lo que es la vida humana en todo su conjunto e historiar la gigantesca lucha del hombre para conocer y conquistar los valores eternos, con sus paradas, fracasos y caídas. La Etnología tiene por fin el establecer con precisión y amplitud en qué consiste lo humano, huyendo de explicaciones racionalistas, artificiales y engañosas o de un apostolado en favor de determinada idea, como por ejemplo el materialismo histórico y el progreso indefinido ${ }^{21}$.

En resumen, Pérez de Barradas concibe la antropología como la ciencia general del hombre que, a su vez, reúne tres disciplinas fundamentales: antropología física, etnología y paletnología (prehistoria). La etnología quedaría definida más concretamente como «el estudio de las manifestaciones culturales del hombre, consideradas en su conjunto como obra del espíritu» ${ }^{22}$. En cuanto a la metodología a seguir, «las teorías evolucionistas y materialistas han sido abandonadas y sustituidas por el método histórico-cultural, fundado especialmente por F. Graebner, B. Ankermann, W. Foy y W. Schmidt» ${ }^{23}$.

\footnotetext{
20 Manual de Antropología, op. cit., 16-17.

21 Ibid., 17.

22 Ibid., 32.

23 J. Pérez de Barradas, La familia (Madrid: Museo Etnológico, 1941), 19.
} 
Es imposible que de esta concepción de la antropología y la etnología surgieran auténticas monografías etnográficas, ni avance metodológico de ningún tipo. El recurso constante, y sin criterios de interpretación etnológica, a la historia, la prehistoria y la antropología física, revestido de un sentido religioso y político concreto, impedirá el desarrollo independiente de la etnología o antropología cultural en lo que podríamos llamar su configuración clásica.

\section{LUIS ÁNGEL SÁNCHEZ GÓMEZ \\ Universidad Complutense, Madrid}

El Instituto «Bernardino de Sahagún», perteneciente al Consejo Superior de Investigaciones Científicas (CSIC), fue el principal centro oficial de investigación en antropología y etnología durante buena parte de la etapa franquista. En el presente artículo se estudian las líneas de investigación potenciadas por su director, J. Pérez de Barradas, y los condicionantes políticos e ideológicos que limitaron su actividad y condujeron a un estancamiento de la antropología cultural en el seno del CSIC.

The Institute «Bernardino de Sahagún», of the High Council for Scientific Research (CSIC), was the main official center for research in anthropology and ethnology during the Franco periord. This paper analyzes the main lines of enquiry laid down by its director J. Pérez de Barradas, and the political and ideological constrains that led CSIC's cultural anthropology to a deadlock. 